\title{
Does Sport Matter?: An Analysis Of The Personality Of Sport
}

Ron Sanchez, (E-mail: ronnyboysanchez@hotmail.com), University of Sydney, Australia Catherine Sutton-Brady, (E-mail: c.sutton-brady@econ.usyd.edu.au), University of Sydney, Australia

\begin{abstract}
This paper examines the intrinsic characteristics of sport and reaffirms the idea that celebrity endorsers bring more to the endorsement process than just their personal qualities. This idea was previously proposed by McCracken (1989) in his transfer of meaning theory. The importance of this research lies in the fact that given the risks associated with celebrity endorsement, marketers must be aware of all factors that influence consumers' evaluations of the celebrity endorsement. The proposition therefore is that an athlete's sport is a factor that influences consumers' celebrity endorsement evaluations. In other words the athlete and his sport cannot be separated.
\end{abstract}

\section{Introduction}

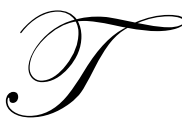

he use of celebrities as endorsers of products and companies is a ubiquitous feature of modern marketing communications." (McCracken 1989) In the USA, 20\% of all commercials incorporate a celebrity endorser (Bradley, 1996). The popularity of celebrities in the execution of communication campaigns is based on the extensive list of benefits celebrity endorsement is expected to achieve (Martin, 1996). However, celebrity endorsement is not without its risks and there is a need to know what factors contribute to the endorsement process. Existing frameworks, like the Source Models are not comprehensive enough to fully account for the entire celebrity endorsement process, since their scope is limited to just the broad personal characteristics an endorser can possess.

This paper is concerned with understanding the celebrity endorsement process at a greater depth than the Source models offer. It is based on the meaning transfer theory proposed by McCracken (1989), which argues that the athlete brings with them more to the product endorsement than just their personal qualities. Along with their personal qualities made visible to the target audience are the intrinsic characteristics of the sport they play, this paper attempts to unearth those intrinsic characteristics and in essence develop an understanding of the personality of sport.

\section{What is a celebrity endorser?}

Two definitions were adopted for the purpose of this study. McCracken (1989) defines a celebrity as a person who enjoys public recognition whatever the reason may be. Celebrities include not only movie, television and music stars but also persons from sport, politics, business, art and the military. An endorser in the context of consumer marketing is a person who willingly supports or appears with a product or service in a way that is communicable to the public. Combining these two concepts, a celebrity endorser is defined as "....any individual who enjoys public recognition and who uses this public recognition on behalf of a consumer good by appearing with it in an advertisement" (McCracken 1989, p.310). The second definition offered by Friedman and Friedman (1979) defines a celebrity as a person recognised by the public for achievements in domains unrelated to the product category being endorsed. This definition goes a step further than McCracken's definition since it imposes a condition on the meaning. The explanation behind this is that if a spokesperson endorsed a product in the same category as their public recognition then they would be perceived to be a product expert endorser rather than a celebrity endorser. The literature on celebrity endorsement is relevant to understanding athlete endorsement since recognised athletes are 'celebrities' in their own right. Athletes are treated with the same superstar fervour as their music and movie counterparts because their superior skills and athletic prowess are admired by fans; the dominant 
role of professional sport in western culture and the major spectacle sport has become through extensive media coverage (Jones and Schumann, 2000). Furthermore, examination of celebrity endorsement literature speaks not only of supermodels, movie, television and music stars as celebrities but notable sporting figures too (Atkin \& Block 1983; Erdogan et al 2001; Hsu \& McDonald 2002; Till 1998a; Till 1998b; Walker et al 1993).

\section{Source Models}

The source models (Source Credibility and Source Attractiveness) stem from the Social Influence and Source Effect theories which posit that certain perceived characteristics of a communication source may have a positive effect on the audience's reception to the conveyed message (Erdogan 1999, p.297). Both models have been adapted by marketers and applied to the selection process of celebrity endorsers. Though there are many personal qualities marketers favour celebrity endorsers to possess, each of the source models narrow the list down to the attributes that would make the endorser most persuasive. The 'source' referred to in these models, is the person or being who is conveying a message to an audience. In this paper the source refers to the celebrity athlete endorser.

\section{The Source Credibility Model}

In the context of celebrity endorsement, source credibility relates to the target audiences' perception of the celebrity having sufficient knowledge and/or experience to provide accurate information (O'Mahony and Meenaghan, 1998). The model contends that the effectiveness of a message depends on the perceived level of expertise and trustworthiness in an endorser (Hovland et al 1953 in Erdogan 1999, p.297). The attribute of expertise is defined as "the perceived ability of the celebrity to make valid assertions" (McCracken 1989, p.311). Expertise is about the knowledge, skills and experience of the celebrity in a given domain (Erdogan 1999).

The second attribute is trustworthiness and is defined as "the willingness of the celebrity to make valid assertions" (McCracken 1989, p.311). Trustworthiness is derived from the celebrity's honesty, integrity and believability as perceived by the audience (Erdogan 1999).

\section{The Source Attractiveness Model}

In addition to the Source Credibility Model, there is the Source Attractiveness Model. In the context of celebrity endorsement, it asserts that the effectiveness of a message depends on the similarity of the celebrity endorser to the target audience; the likeability of the celebrity endorser; and the familiarity of the celebrity endorser to the target audience (McGuire, 1985).

Adapting McCracken's (1989) explanation of these source attributes to celebrity endorsement, the following definitions are provided: ' 'familiarity' is defined as knowledge of the [celebrity] through exposure in the media; 'likeability' as affection for the [celebrity] as a result of the [celebrity's] physical appearance and/or behaviour; and 'similarity' as a supposed resemblance between the [celebrity] and the target audience." (p.311)

In the case of marketing communications featuring celebrity endorsers, most emphasis has been on physical attractiveness in terms of beauty, physique and sex appeal rather than other source attributes mentioned above. Physical attractiveness is such a powerful attribute that it has been shown to be a key driver behind other worthwhile personal attributes. For instance, physically attractive people are often assumed to be intelligent and 'switched on' (Erdogan, 1999 p.301). Some findings in social research report that physical attractive people elicit positive impressions upon initial social contact (Miller 1970); achieve greater social acceptance (Kleck et al, 1974) and are perceived to be more sensitive, kind, interesting, strong, poised, modest, sociable and outgoing than persons of lesser physical attractiveness (Berscheid and Walster, 1974).

The overwhelming evidence from social research in support of the physical attractiveness attribute makes it a desirable trait for celebrity athlete endorsers to possess and many of them do, most commonly in the form of their highly conditioned physique necessary for top performance in their sport. Some athletes are blessed with facial beauty as well (eg. David Beckham, Oscar De La Hoya, Anna Kournikova) further adding to their attractiveness. In 
the case of marketing communications, however, experimental and survey results testing the impact of 'physical attractiveness' are surprisingly mixed.

Baker and Churchill (1977) found that the affective component of attitude ${ }^{1}$ toward print advertisements featuring attractive models was more favourable than the same print advertisement featuring a model regarded as unattractive. Similarly, Kahle and Homer (1985) showed product liking, brand and product recall was significantly greater ${ }^{2}$ when respondents viewed a magazine advertisement that featured an attractive celebrity as opposed to a celebrity deemed unattractive. Results show that attractive endorsers have a positive influence on the affective and cognitive components of attitude.

However, on the conative component of attitude which influences purchase intentions and purchasing, results are equivocal. Kahle and Homer (1985) found a significant difference, in favour of attractive celebrity endorsers, on purchase intentions of razor blades. ${ }^{3}$

The point of departure is found in Caballero et al (1989), where the authors conducted a field study to avoid the methodological limitations they discovered in the studies discussed above. ${ }^{4}$ The authors point out that "the implicit demands of the psychology laboratory may often lead subjects to adopt highly logical modes of cognitive functioning and, as a consequence, to underutilize attractiveness information in their opinions [thereby discounting affective component of attitude]." (Chaiken, 1979)The results of this study attest that the differential effect between the attractive and less attractive endorser on purchase intention for soft drink and cheese was not significant. In fact, an earlier field study by Caballero and Solomon (1984) that placed displays at the point of purchase showed that sales of facial tissues were actually significantly higher where display featured the less attractive female model, as also was the case with coffee advertisements featuring 'unattractive' female models rated by male subjects on the same component of attitude in Churchill and Baker (1977).

Most importantly, the studies also highlight the impact of other variables on purchase intentions and purchase behaviour. All the studies mentioned performed analysis of variance (ANOVA) when they examined the impact of attractiveness on dependent variables such as advertisement evaluation; brand and product recall; purchase intention and actual purchasing. The studies demonstrate that variables such as the gender of the featured model (Caballero and Solomon 1984; Kahle and Homer 1985; Baker and Churchill 1977); the type of product endorsed (Friedman and Friedman 1979; Ohanian 1990) involvement level (Kahle and Homer 1985) and gender of the respondents (Caballero and Solomon 1994) acted in concert with physical attractiveness to jointly affect the dependent measures. Furthermore, the type of products being advertised also impacted on the dependent measures of interest (Baker and Churchill 1977; Caballero et al 1989; Caballero and Solomon 1984).

It is evident that physically attractive celebrities do not always guarantee the benefits outlined as the Source Attractiveness model predicts. Langmeyer and Shank (1994 p.27) use several examples in marketing practice to justify their argument that "being physically attractive... does not seem to be enough - it seems to be a necessary yet not sufficient condition." The Source Models overall, expect that if celebrity endorsers possess the prescribed attributes then the message will be persuasive. On a conceptual level this assertion is flawed since more factors in the celebrity endorsement process impact upon the message effectiveness than just the personal attributes of the celebrity endorser. "...The celebrity world is something richer and more complicated than a collection of merely credible and attractive individuals" (McCracken, 1989, p313) and this must be accounted for in the examination of celebrity endorsement.

There is also evidence in marketing practice that defies the source models expectations. For example, Shaquille O'Neal (basketball superstar) heralded in the early 1990's as the next premier celebrity athlete endorser after Michael Jordan (Starr 1995), was dumped by Reebok in 1998 as an endorser for its' line of basketball shoes. O'Neal definitely meets the requirements of the source models; "[he] gave Reebok credibility as a performance brand but... Mr O'Neal developed a rep as 'another big man who can't sell shoes."' (Jensen 1998) McCracken (1989) notes several celebrities who failed in their product endorsements despite fulfilling the source models' requirements. 
Therefore, the source models should not be used a lone guide in the selection process of celebrity endorsers because their scope in the realm of celebrity endorsement is incomplete. The implications of variables apart from the source's attributes affecting consumers' evaluation of celebrity endorsements, is the possibility that another factor such as the sport, which makes up a large part of the celebrity athlete's persona will also impact on this measure. An alternative to the Source Models which provides greater scope into celebrity endorsement has been proposed and will now be discussed.

\section{The Theory of Meaning Transfer}

Unlike the Source Models, the Meaning Transfer paradigm takes a holistic approach to the study of celebrity endorsement. The theory proposed by McCracken (1989) originates from his previous work about the diffusion of cultural meanings that reside in consumer societies and is applied to celebrity endorsement. At the heart of this theory is the proposition that a dynamic process of culturally endowed meanings reside in the realm of celebrity endorsement and to a bigger extent consumer society. In the particular context of celebrity endorsement, McCracken (1989) summarises celebrity endorsement to a three stage process.

The theory contends that a celebrity endorsement is successful when an "association is fashioned between the cultural meanings of the celebrity world... and the endorsed product" (McCracken, 1989, p.313) and then finally the cultural meanings move from the product to the consumer in the act of consumption. An examination of each stage of the theory will now be conducted.

\section{Stage 1: The Cultural World}

The theory begins in the cultural world and posits that celebrity endorsers including celebrity athletes are loaded with an array of symbolic meanings that originate in the culturally constituted world. Categories of symbolic meanings include gender, lifestyle, status, social class, ethnicity, time and place.

From the celebrity athlete perspective, the symbolic properties the athlete is publicly recognised for are derived mainly from their career in the sporting arena since this is where they became known to the public (Martin, 1996, p.29). In a sense, it is the sport that begets the celebrity of the athlete. The celebrity athlete brings his/her own personality traits to the endorsement as the Source Models say; yet at the same time the sport and its symbolic meanings becomes a part of the celebrity athlete's image. "Celebrity endorsers embody symbolic meanings...that go beyond those directly contained within themselves." (Langmeyer and Walker, 1991 p.364) Martin (1996) contends that the meanings that go beyond the athlete are actually those of the sport's meanings and characteristics. In effect the athlete become's synonymous with the sport.

\section{Stage 2: The Endorsement}

The next stage of the process is the endorsement; where a diffusion of meaning takes place. The theory posits that the celebrity loaded with symbolic meanings passes them onto the product by the very act of endorsing it. The vehicle by which this transfer occurs is through advertising (ibid, p.315). What McCracken eludes to here is that a product endorsement contract between the celebrity athlete and the company comes to life when it is publicly expressed by a tangible vehicle; that being advertising. Thus people's evaluations of the celebrity endorsement, the measure of interest in this research occurs when the advertisement is viewed by the consumer.

\section{Stage 3: Consumption}

The final stage is the act of consumption, moreover the consumers' act of claiming the meanings imbued in the product into their own lives. This stage is dependent upon the successful execution of advertising leading to consumers' perception of transfer from celebrity to product.

This paper is largely concerned with the content outlined in stage one of the meaning transfer theory; whether the sport of the celebrity athlete and its symbolic meanings, which constituting a large part of their persona 
and inevitably brings to the product endorsement, influences consumer's evaluation of the celebrity endorsement stage two of this theory. There are two worthwhile reasons behind this enquiry. Firstly, given the risky payoff structure of celebrity endorsement it would be wise to explore all possible factors that can influence its effectiveness. Secondly, sport is an essential part of Australian leisure and culture and is rich in meaning.

Only one study by Martin (1996) undertakes this same specific enquiry into celebrity athlete endorsement. One important implication to marketing communication decision making Martin (1996, p.28) highlights is if the type of sport doesn't affect consumer's response to the endorsement then ceteris paribus, searching for the athlete with the most appropriate characteristics for the non-sport product endorsement, regardless of the sport, at the least cost is the best decision strategy. If sport does have a significant impact then marketers have to be even wiser in their selection of a celebrity athlete to be a product endorser.

\section{Methodology}

The research instrument in this study was a combination of structured and unstructured, undisguised questionnaire, administered in a self-report format to the convenience sample of undergraduate students. This method was chosen because the information sought can be gathered with this method and was most efficient in eliciting respondents' answers. 97 undergraduate students constituted the convenience sample employed in this study. The student respondents completed the survey during their normal class time. 100 students were enrolled in this course of study therefore a response rate of $97 \%$ was achieved for this convenience sample.

The undergraduate age group is a primary target market for the products endorsed by celebrity athletes making a student sample suitable to this study (Martin, 1996). This is a plausible contention given that university students are knowledgeable about sport (Martin, 1994) and have ample opportunity to play and watch sport.

Respondents evaluated six hypothetical celebrity endorsements (3 sports x 2 products). Respondents envisaged a famous athlete from a particular sport endorsing a non-sport product in the form of a television commercial and asked to evaluate each according to criterion that covers all three components of attitude (cognitive, affective and conative Schiffman, 2001). A celebrity endorsement most vividly comes into fruition in the form of a television commercial and this method of celebrity endorsement best elicits consumer's attitude. The basis of respondents' evaluation for each celebrity endorsement was in the form of a scenario where the respondent imagines viewing the television commercial which tangibly represents the celebrity athlete endorsing the non-sport product. This method of evaluation was chosen because it was consistent with stage two of the Meaning Transfer Theory (McCracken, 1989) that the impact of the sport is best captured in advertising because it is a visible expression of the celebrity endorsement.

In addition to the endorsement evaluations and the celebrity athlete, respondents also provided three characteristics that describe or are associated with each of the sports in the study. This was conducted in order to address research questions two and three. A free association technique was employed to measure the characteristics of each sport rather than Martin's (1996) method of employing a list of pre specified scale items, some of which do not make logical sense when asked in relation to the sports employed. The open ended question format is much better at eliciting the salient characteristics of the sport.

Golf, soccer and boxing were the sports nominated in the study. These sports were chosen because they are international sports played around the world. Sports that are played predominantly in Australia were avoided out of concern that international respondents (a significant proportion of undergraduate students in this course were from another country) would not know enough about a sport like Rugby League, let alone the its star players to make informative assessments.

These sports were chosen because even on an intuitive level they are vastly different from one another. If sport impacts upon the dependent measure as hypothesised then the differential effect of sport on the dependent variable will best be observed with sports that maximally differ from one another. Golf, soccer and boxing differ from each other on a variety of dimensions such as physical attributes - contact versus non-contact, team versus 
non-team sport; the imagery of players and the pace of the sports. The choice of golf and soccer in particular according to this proposition of dissimilarity is supported by Martin (1994).

\section{Findings}

For the purposes of this paper the findings are discussed only in relation to the personalities of the sports. It is outside the scope of the paper to investigate the impact on the endorsement process, this will be discussed in suggestions for future research.

H1: The sports (incorporated in this research) will differ on the basis of the characteristics respondents ascribe to each sport.

H10: The sports (incorporated in this research) will not show evident differences in the characteristics respondents ascribe to each sport.

The hypothesis of this research is that respondents will have different characteristics in mind when thinking of different sports. Another way of interpreting this hypothesis is that it is a manipulation check of the stimulus. Differences amongst the sports are required in order to assess their differential effect and this hypothesis is a means of doing so. The qualitative analysis of the characteristics provided by the respondents for each sport was conducted in order to address this question. "What are the particular sets of characteristics of particular sports lie in the minds of consumers?"

Words and phrases were grouped together according to a higher order theme. A discussion about the main categories that emerged and the particular characteristics that comprise them will be provided for each sport followed by a frequency table for the categories identified.

\section{The Personality of Golf}

1. Golf Environment - The most common category of characteristics identified was about the natural environment golf is played in. The words green and grass or the phrase 'green grass' or 'golf green' combined to be the most frequent type of association in this category $(45 \% \text { combined })^{5}$. Reference to the nice, sunny weather (18\%), nature (5\%), and the nice view on the golf course $(5 \%)$ were also parts this of category. The golfing environment was also described as relaxing and quiet (8\%).

2. Player Imagery - The player imagery theme is about the persons respondents' identified when asked this question. The most common persons mentioned were Tiger Woods (24\%) and Greg Norman (14\%). Apart from the celebrities identified there was a frequent view of golf players being old and mature (22\%) and to a lesser extent being white $(11 \%)$.

3. Wealth and Affluence - The words wealth and rich were very frequent associations used in varying contexts. In one instance it was said that golf is a game for the wealthy and rich (8\%) and in the most common instance the words 'rich', 'rich people', 'wealth' and 'wealthy people' (62\%). The expensiveness of the sport was the next most common association (22\%). Some associations were about the lucrative cash prizes offered in professional golf $(6 \%)$. Golf's reputation as being rich and wealthy and its players sharing the same qualities too was very notable in this sample.

4. Upper or High Class - A theme closely related to wealth and affluence is the view of golf being upper (high) class (21\%), part of high society (3\%), prestigious (17\%), luxurious (7\%), posh (7\%), conservative $(10 \%)$, and successful (7\%). A few negative comments within this theme were also present, namely that golf is considered pretentious (4\%) and snobby (7\%).

5. Personality Traits - The most dominant personality trait ascribed to golf is that it is boring and uninteresting (62\%). Contrary to this trait but much less apparent is that golf is fun, social, recreational and enjoyable - a relaxing sport ( $21 \%$ combined). Golf was considered 'old' (17\%), and this is most likely to be highly correlated with golf players thought to be 'old'.

6. Physical and Mental Aspects of the Sport - Physically, golf is regarded as a slow game (43\%) that requires precision (7\%). Concentration, discipline, challenge and determination are mental associations of golf (29\% combined). 
7. Descriptive Golf Equipment and Accessories - This category refers to golf apparel. The type of clothing and accessories varied considerably and given the small size of the category, a single image of a golfer's clothing could not be established. Golfers wear chequered or akubra hats; wear conservative or boring clothing whilst others say nice clothing; long, tartan trousers; ugly shoes; Ralph Lauren polo t-shirts and caps and classic brands.

Table 1 below summarises the categories of characteristics people associate with golf.

\begin{tabular}{|c|c|c|}
\hline \multicolumn{3}{|c|}{ Categories of Golf's Characteristics and Meanings } \\
\hline Theme & $\begin{array}{l}\text { Number of } \\
\text { Characteristics that } \\
\text { comprise category }\end{array}$ & Frequency of category $(\%)$ \\
\hline 1. Golf Environment & 14 & 17 \\
\hline 2. Player Imagery & 12 & 16 \\
\hline 3. Wealth and Affluence & 7 & 13 \\
\hline 4. Upper Class / High Society & 13 & 12 \\
\hline 5. Golf Personality Traits: & & \\
\hline a) Boring & 4 & 11 \\
\hline b) Fun / Social & 7 & 4 \\
\hline c) Old & 5 & 3 \\
\hline 6. Physical and Mental Aspects of the Sport & 13 & 10 \\
\hline 7. Golf Apparel and Accessories & 12 & 6 \\
\hline 8. Miscellaneous & 7 & 7 \\
\hline Total & 93 & 100 \\
\hline
\end{tabular}

\section{The Personality of Soccer}

The characteristics for soccer varied much more than golf and boxing. A lot of key words and phrases respondents listed for this question related more to their attitude to soccer rather than symbolic characteristics of the sport.

1. Soccer Teams and Competitions - The most common category of soccer associations was about particular soccer teams and the world cup. National teams such as England, Australian, Italy and Brazil were the national sides mentioned ( $31 \%$ combined). Renowned teams from competitive leagues like Manchester United and Real Madrid were mentioned. What dominated this category the world cup competition (44\%).

2. The Soccer Spectacle - This category of characteristics consisted mainly of single words that describe what is seen on the soccer field. The scoring of goals was the most common association (25\%). Other things that are part of the soccer spectacle was acting (6\%), action (6\%), diving (3\%), free kicks (3\%), offside (3\%), passion $(6 \%)$, penalties $(6 \%)$, running $(6 \%)$, success $(3 \%)$, team play $(3 \%)$ and war $(3 \%)$.

3. The Crowd and Atmosphere - This is closely related to the spectacle of soccer but instead focuses on what is surrounding the game on the field. Respondents' spoke of the atmosphere at a soccer match (35\%), a cheering crowd (10\%) and also a 'crazy' crowd (15\%) were mentioned. Particular reference to the size of the crowd and the stadiums used were also made.

4. Physical Aspects of Soccer - Soccer was characterised as a highly skilled sport (20\%), fast pace (20\%), athletic $(15 \%)$ and energetic $(5 \%)$. It was also regarded as strenuous $(5 \%)$, requiring power $(5 \%)$ and a lot of training $(5 \%)$.

5. Physical Image Of Soccer Players - The most frequent physical trait of soccer players was their attractiveness (25\%). Words such as 'handsome', 'good looking' and 'cute' were used. Soccer players were also considered to be fit (20\%) and healthy (10\%).

6. Soccer Celebrities - As in golf, celebrities from the sport were also mentioned and they were the celebrities pictured in each of the product endorsement questions. The three soccer players mentioned were David Beckham (55\%), Harry Kewell (18\%) and Ronaldo (27\%).

7. Soccer Personality Traits - The first trait is Enjoyable - consisting of the key words, exciting (37\%), fun to play $(26 \%)$ and watch (16\%), interesting (16\%) and great (5\%). The second trait is Popular - consisting of 
the key words, popular (44\%), global (13\%) and common (7\%) and it considered to be the world sport $(7 \%)$.

8. Money - Respondents also said that there is lots of money in the sport (11\%), whilst others just said the words money (55\%) or rich (22\%) and others pointed out the 'big money contracts' $(12 \%)$.

Table 2 summarises the categories of characteristics associated with soccer

\begin{tabular}{|l|c|c|}
\hline \multicolumn{2}{|c|}{ Categories of Soccer Characteristics and Meanings } \\
\hline \multicolumn{1}{|c|}{} & $\begin{array}{l}\text { Number of } \\
\text { Characteristics that } \\
\text { comprise the } \\
\text { category }\end{array}$ & $\begin{array}{c}\text { Frequency of the } \\
\text { category }(\%)\end{array}$ \\
\hline Theme & 12 & 27 \\
1. Soccer Teams and Competitions & 15 & 15 \\
2. The Soccer Spectacle & 8 & 9 \\
3. Crowd / Atmosphere & 8 & 10 \\
4. Physical Aspects & 9 & 8 \\
5. Physical Image of Soccer Players & 3 & 9 \\
6. Soccer Celebrities & 5 & 7 \\
7. Personality Traits & 6 & 4 \\
a) Enjoyable & 4 & 6 \\
b) Popular & 14 & $\mathbf{1 0 0}$ \\
\hline
\end{tabular}

\section{The Personality of Boxing}

The associations of boxing were much less diverse than golf and soccer and concentrated amongst fewer themes.

1. Personality Traits of Boxing - All of the associations in this category are words that can describe humans and therefore this category was dubbed the personality traits of boxing. Numerous but related associations made up this particular category, the majority $(72 \%)$ of them were negative. The most frequent of the negative associations was the sport's violence (21\%). Other key words that related to violence were abusive, aggressive, brutal, cruel, dangerous, dirty, hard, psycho, rough, rape, tough, ugly, vicious and wild (40\%), whilst other negative qualities were stupid and rude. Another sub category of traits identified was the perception of boxing as corrupt, criminal and a game for thugs (9\%). The remaining minority of personality traits were power, fast, endurance and exciting.

2. Physical Outcomes / Risks - This category of characteristics all pointed to the physical consequences and risks of boxing. Blood was the most frequent (45\%), followed by sweat (16\%) and knock outs $(16 \%)$. Types of consequential injuries included bruising, brain damage, swollen eye, headaches, pain and torn ears $(21 \%)$.

3. Physical Image of Boxers - This category of characteristics provides a physical description of boxers. The various physical properties of boxers' include muscles (21\%), possession of a large frame (7\%), healthy / highly conditioned (14\%), skilful (4\%), strong (18\%) and speed (4\%). Boxers were thought to be male $(25 \%)$ and of African descent (7\%).

4. Spectacle - Two types of associations comprised this category. The first referred to a description of the audience. Key words included pay TV, pubs, big screen televisions and cheering crowds. The second element is about the content of the spectacle - what is viewed by the audience. Key words included fights, punches, championships and titles, defeat and victory.

5. Boxing Celebrities - The following celebrities were mentioned as answers to the association question Muhammad Ali, Anthony Mundine, Evander Holyfield, the Klitschko brothers, Lennox Lewis, Rocky, Mike Tyson and Don King. 


\begin{tabular}{|c|c|c|}
\hline \multicolumn{3}{|c|}{ Table 3 Categories of Boxing Characteristics and Meanings } \\
\hline & $\begin{array}{l}\text { Number of } \\
\text { Characteristics } \\
\text { that comprise the } \\
\text { category }\end{array}$ & $\begin{array}{c}\text { Frequency of } \\
\text { the category } \\
(\%)\end{array}$ \\
\hline Theme & 29 & 41 \\
\hline 1. Personality Traits of Boxing & 17 & 26 \\
2. Outcomes / Physical Consequences / Risks & 10 & 12 \\
3. Physical Image of Boxers & 7 & 11 \\
4. Spectacle & 9 & 6 \\
$5 . \quad$ Boxing Celebrities & 16 & 5 \\
6. Miscellaneous & $\mathbf{8 8}$ & $\mathbf{1 0 0}$ \\
\hline Total & & \\
\hline
\end{tabular}

\section{Conclusions and Implications}

The aim of this paper was to uncover the characteristics of the sports that lie in people's mind. By categorising the hundreds of characteristics discovered during the collection of data this was possible. Examination of each sport clearly shows that the characteristics for each sport are dissimilar in their characteristics and hence their image. The fact that such rich and vivid images of the sports emerged from the data gives strong support for the empirical validity of stage 1 of the meaning transfer theory (McCracken, 1989); that within a consumer's mind there exists meanings originating in the world of sport (one of many cultural realms in society) and these meanings are activated when a particular sport is thought of.

Golf has the personality of being old aged, slow and only mildly relaxing and enjoyable, whereas soccer is much livelier, exciting and interesting. The personality of boxing highlights another contrast between the sports. Its personality is described as violent, aggressive, abusive and corrupt, all of which are negative traits. The sample also said that golf reflects wealthiness and being rich and similarly some people ascribed golf to be a game for rich people. However, for soccer and boxing respondents commented more about the game itself and what is being seen when the game is watched. For soccer, respondents pictured goals, free kicks and victory celebrations. Closely related to spectacle of soccer was the atmosphere in the stadium and the fans watching a match, whereas boxing is watched not live but via large screen TV at the pub. The nature of what is seen in boxing is quite a contrast to soccer and consisted of knockouts, blood, sweat and punches.

Given the differences in categories of characteristics uncovered for each sport, we can conclude that the sports researched do differ in terms of the characteristics respondents associate with the sports and thus support the hypothesis H1. In light of this discussion marketing managers must not choose an athlete to endorse the company or its products solely on their affordability, credibility and likeability. Marketers are also constrained by an additional factor in their choice of celebrity athlete endorser and that is the athlete's sport.

\section{Suggestions for future research}

Given that we have found that popular sports differ immensely in their characteristics, the obvious next step is to investigate whether sport and its intrinsic characteristics can affect people's evaluation of the celebrity endorsement. It is our belief based on our findings that sport does matter, however in terms of the celebrity endorsement process this does need further investigation to ascertain to what extent the sport matters in evaluating the celebrity endorsement.

\section{References}

1. Atkin, C. and Block, M. (1983) "Effectiveness of Celebrity Endorsers" Journal of Advertising Research, 23(March) p.57-61.

2. Baker, M.J. and Churchill, G.A. (1977) "The Impact of Physically Attractive Models on Advertising Evaluations", Journal of Marketing Research, 14(November) p.538-555. 
3. Berscheid, E. and Walster, E. (1974) "Physical Attractiveness" in Advances in Experimental Social Psychology, (ed) Berkowitz, L. Academic Press, New York.

4. Caballero, M.J., Lumpkin, J.R. and Madden, C.S. (1989) "Using Physical Attractiveness as an Advertising Tool: An Empirical Test of the Attraction Phenomenon", Journal of Advertising Research, 29(August/September) p.16-22.

5. Caballero, M.J. and Pride, W.M. (1984) "Selected Effects of Salesperson Sex and Attractiveness in Direct Mail Advertisements", Journal of Marketing, 48 (winter) p.94-100.

6. Caballero, M.J. and Solomon, P.J. (1984) "Effects of Model Attractiveness on Sales Response", Journal of Advertising, 13(1) p.17-23.

7. Chaiken, S. "Communicator Physical Attractiveness and Persuasion", Journal of Personality and Social Psychology, 37(2) p.1387-97.

8. $\quad$ Erdogan, B.Z. (1999) “Celebrity Endorsement: A Literature Review”, Journal of Marketing Management, 15(4) p.291314.

9. $\quad$ Erdogan, B.Z., Baker, M.J. and Tagg, S. (2001) "Selecting Celebrity Endorsers: The Practitioners Perspective", Journal of Advertising Research, 41(May/June) p.39-48.

10. Friedman, H.H. and Friedman, L. (1979) "Endorser Effectiveness by Product Type", Journal of Advertising research, 19(October/November) p.63-71.

11. Hsu, C. and McDonald, D. (2002) "An examination on Multiple Celebrity Endorsers in Advertising”, Journal of Product and Brand Management, 11(1) p.19-29.

12. Jensen, J (1998) "Marketing Miscues Prompt Re Branding of L.A. Lakers Star", Advertising Age, 69(11)

13. Kahle, L.R. and Homer, P.R. (1985) "Physical Attractiveness of the Celebrity Endorser: A Social Adaptation Perspective", Journal of Consumer Research, 11(March) p.954-961.

14. Kleck, R.E, Richardson, S.A, and Ronald, L. (1974) "Physical Appearance Cues and interpersonal Attraction in Children" Child Development, 45(2) p.305-310.

15. Langmeyer, L. and Shank, M (1994) "Managing Beauty - Products and People" Journal of Product and Brand Management, 3(3) p.27-38.

16. Langmeyer, L. and Walker, M. (1991) “A First Step to Identify the Meaning in Celebrity Endorsers" Advances in Consumer Research, 18(1) p.364-371.

17. Martin, J.H. (1994) "Using a Perceptual Map of the Consumer's Sport Schema to Help Make Sponsorship Decisions" Sport Marketing Quarterly, 3(3) p.27-33.

18. Martin, J.H. (1996) "Is the Athlete's Sport Important when Picking an Athlete to endorse a Non-sport Product" Journal of Consumer Marketing, 13(6) p.28-43.

19. McCracken, G. (1989) "Who is the Celebrity Endorser? Cultural Foundations of the Endorsement Process", Journal of Consumer Research, 16(December) p.310 - 321.

20. McGuire, W.J. (1985) "Attitudes and Attitude Change”, in Handbook of Social Psychology, (Eds.) Gardner, L and Aronson, E. Vol 2, Random House, New York, p233-346.

21. Miller, A.G. (1970) "The Role of Physical Attractiveness in Impression Formation", Psychometric Science, 19(2) p.241-43.

22. O’Mahony, S. and Meenaghan, T. (1997) “The Impact of Celebrity Endorsements on Consumers”, Irish Marketing Review, 10(2) p.15-24)

23. Ohanian, R. (1991) "The Impact of Celebrity Spokespersons' Perceived Image on Consumers' Intention to Purchase”, Journal of Advertising Research, 31(1) p.46-52.

24. Schiffman, L., Bednall, D., Cowley, E., O’Cass, A., Watson, J., Kanuk, L. (2001) Consumer Behaviour, Frenchs Forest, Prentice Hall.

25. Starr, M. (1995) “The \$16 Million Man” Newsweek, 125(18) p.72.

26. Till, B.D. (1998a) "Using Celebrity Endorsers Effectively: Lessons from Associative Learning” Journal of Product and Brand Management, 12(5) p.400-409.

27. Till, B.D. (1998b) "Matching Products with Endorsers: Attractiveness Versus Expertise" Journal of Consumer Marketing, 15(6) p.576-588.

28. Walker, M., Langmeyer, L., and Langmeyer, D. (1993) "Commentary: Celebrity Endorsers. Do You Get What You Pay For?" Journal of Product and Brand Management, 2(3) p.36-43.

\footnotetext{
${ }^{1}$ Affective component consisted of appealing; impressive; eye-catching; and attractive.

${ }^{2}$ Based on the ANOVA, significance was $\mathrm{p}<0.025$

${ }^{3}$ The product was manipulated in terms of a reward being offered in order to create both high and low involvement treatments. Significance $\mathrm{p}<$ 0.005

${ }^{4}$ Video advertisements were used instead of print advertisement; the study was conducted in store rather in a 'laboratory' type setting with a sample of actual store patrons and not students. The study was based on the effect of attractiveness and not on celebrities.

${ }^{5}$ The percentages within the themes are calculated as the frequency of a particular association or set of common associations as a percentage of the sum of the frequencies of total associations within the theme.
} 